\title{
Right out of the box: How to situate metaphysics of science in relation to other metaphysical approaches
}

\section{Alexandre Guay \& Thomas Pradeu}

To appear in a special issue of Synthese entitled

New Metaphysics of Science

edited by Max Kistler

\author{
Alexandre Guay \\ Professor \\ Institut supérieur de philosophie, \\ Université catholique de Louvain \\ Place Cardinal Mercier 14, Bte L3.06.01 \\ 1348 Louvain-la-Neuve \\ Belgium \\ \& \\ Centre interuniversitaire de recherche sur la science et la technologie \\ Université du Québec à Montréal \\ C.P. 8888, succ. Centre-ville \\ H3C 3P8 Montréal (Québec) \\ Canada \\ alexandre.guay@uclouvain.be \\ www.uclouvain.be/alexandre.guay

\section{Thomas Pradeu} \\ CNRS Senior Investigator in Philosophy of Science \\ Immunology Unit ImmunoConcEpT, UMR5164, CNRS \& University of Bordeaux \\ 146 rue Léo Saignat \\ 33076 Bordeaux \\ France \\ \& Institut d'histoire et de philosophie des sciences et des techniques, CNRS \& Pantheon-Sorbonne \\ University \\ 13 rue du Four \\ 75006 Paris \\ France \\ thomas.pradeu@u-bordeaux.fr \\ https://www.immuconcept.org/conceptual-immunology/
}

\section{Introduction}

The last two decades have seen the rise of the term "metaphysics of science" (or, sometimes, "scientific metaphysics"), used to describe a specific philosophical project, which aims at developing an ontology, or worldview, based on current science (e.g., Redhead 1995; Ladyman and Ross 2007; Maudlin 2007; Esfeld 2012, 2013; Morganti 2013; Ross, Ladyman and Kincaid 2013; 
French 2014). Philosophy of science has classically been extremely critical of metaphysics (e.g., Carnap, Hahn, and Neurath 1929; Carnap 1931), so the very phrase "metaphysics of science" would have aroused suspicion in the past. Recently, however, an increasing number of philosophers have defended the view that, in the words of the Society for the Metaphysics of Science, "a key area of inquiry for naturalistic philosophers is a form of 'metaphysics' in what has recently been dubbed the 'metaphysics of science': the abstract examination of ontological issues as they arise within, or growing out of, the sciences and their findings, concepts, models, theories etc." "What metaphysicians of science seek, therefore, is the possibility of enriching metaphysical debates by involving them with lessons taken from current sciences (Ney 2012).

Two different interpretations of this general idea have cropped up in recent literature (see Figure 1). The first can be called "metaphysics applied to science". It states that major concepts of traditional metaphysics - for example "causality", "law" or "individual" - can be enriched by a glance at current sciences. Metaphysics applied to science is done mainly by philosophers who portray themselves as "metaphysicians" (e.g., Bird 2007; Lowe 2006; Chakravartty 2007; Mumford and Tugby 2013). These philosophers have been inspired by several founders, including Lewis (1973); Armstrong (1978) and Ellis (2001). Here the prime focus is on classic questions of metaphysics, and the aim is to illustrate metaphysical points with scientific examples.

The second interpretation can be called "scientific metaphysics". It states that science constitutes the best starting point and the best guide to metaphysics; it is done mainly by philosophers who portray themselves as "philosophers of science" (e.g., Redhead 1995; Ladyman and Ross 2007; Maudlin 2007; Ross, Ladyman and Kincaid 2013). Here the starting point is clearly science; metaphysics arrives later and builds upon scientific results. For example, when statistical mechanics was extended to the quantum realm, it was noticed that in order to obtain the empirically adequate statistics, particle indistinguishability had to be assumed. As their classical counterparts, quantum particles of the same kind can be counted, but contrary to them they cannot be distinguished. This induced two main metaphysical responses: 1) quantum particles are not individuals; ${ }^{2}$ 2) the metaphysical notion of individuality should be changed in order to accommodate weak distinguishability. ${ }^{3}$ Both responses are putting science before metaphysics. The present paper focuses mainly on the second of these two interpretations, namely "scientific metaphysics," though we will also explain how our own view relates to the first interpretation, namely "metaphysics applied to science."

\footnotetext{
1 Website of the Society for the Metaphysics of Science (https://sites.google.com/site/socmetsci/what-is-themetaphysics-of-science-1). Importantly, several members of this Society are - following a distinction we make in this paper - proponents of "metaphysics applied to science" rather than "scientific metaphysics", and therefore do not all adopt the three principles of the centrality of physics, universalism, and realism that we describe below.

${ }^{2}$ Assuming ontological reductionism to physics, this response would imply that there is no individual in nature and that the related metaphysical notion is irrelevant.

${ }^{3}$ For more details about quantum individuality, see (French and Krause 2006).
} 


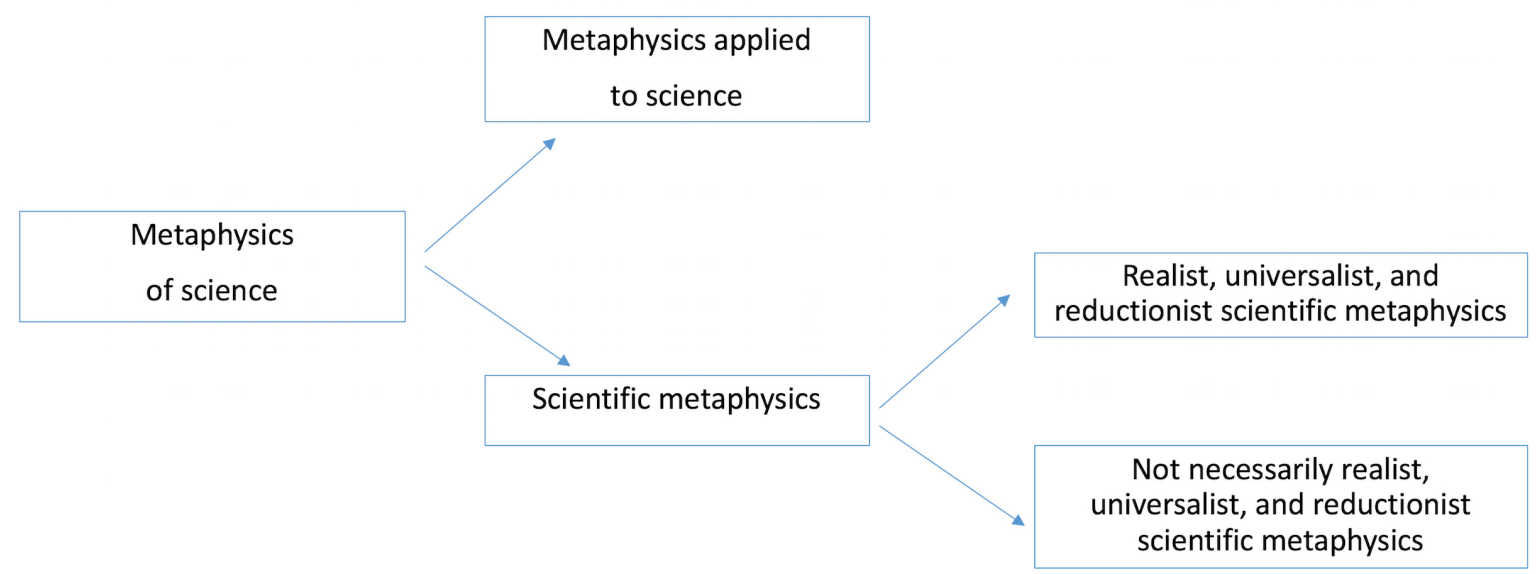

Fig. 1. Different understandings of the phrase "metaphysics of science" coexist in current philosophical literature.

Several versions of scientific metaphysics can be distinguished: the modest version states that our worldview can be improved by the integration of some developments of current science, while an intermediate version says that our worldview must take into account current science, and finally the strongest version claims that our worldview must be based only on current science. Naturally, the strongest version leads to overt opposition to at least some forms of traditional metaphysics. In this renewed battlefield, the phrase "naturalized metaphysics" (or "naturalistic metaphysics") plays a special role, often with the idea that time is ripe for a naturalized metaphysics to replace other kinds of metaphysics - as famously claimed by Ladyman and Ross:

If metaphysics is to be part of the pursuit of objective knowledge, it must be integrated with science. Genuinely naturalized metaphysics must go beyond mere consistency with current science; it must be directly motivated by and in the service of science. (Ladyman and Ross 2013: 109). ${ }^{4}$

Nevertheless, claims of this sort raise many questions, including the one that lies at the heart of this paper: What is the "target" of this strong version of scientific metaphysics? In other words, what are exactly these other kinds of metaphysics that naturalized metaphysics attacks and seeks to replace? The target is sometimes said to be "a priori" metaphysics, but in other cases it is referred to as "analytic" metaphysics, or "intuitive metaphysics", or "armchair" metaphysics (Ladyman and Ross 2007: 10; see also Esfeld 2013: 600). These conflicts between different metaphysical approaches have become extremely vivid in the current philosophical landscape, but they remain quite vague and confused.

In this paper, we show that these tensions need to be refined, and we defend the view that metaphysics of science must be combined with other, more traditional, forms of metaphysics. More precisely, we argue that recent scientific metaphysics has made two detrimental oversimplifications. First, it has not identified in a clear and precise way its target, that is, the metaphysical project it opposes. Second, it has tended to reduce science-based metaphysical approaches to realism, ontological universalism, and physical reductionism - three tenets which, we claim, are not necessary components of a metaphysics of science project. In our view, this double

\footnotetext{
${ }^{4}$ See also the quotation from Ladyman and Ross (2007) in the next section.
} 
oversimplification has led to an impoverished framework, and, consequently, weakens the debate with other forms of metaphysics. ${ }^{5}$

In short, we accept the modest and even the intermediate versions of scientific metaphysics (i.e., we agree that our worldview must take into account current science), but we forcefully reject the strong version (i.e., the claim that our worldview must be based only on current science), and we also dismiss the idea that metaphysics of science should necessarily be realist, universalist, and reductionist.

An important objective of this paper is therefore to expand the scope of the field called "metaphysics of science" by suggesting that some of the features associated with the way this field has developed in the last fifteen years could be contingent rather than necessary. We want to leave open different avenues for metaphysics of science - including the possibility that metaphysics of science could be non-realist, not based on physics only, and that it could be grounded in a priori rather than a posteriori considerations. If we can all agree that metaphysics is the study of ultimate reality (van Inwagen 2002), it is not obvious that this reality is reducible to physics and in principle knowable. We are perfectly aware that non-realism is not the path that recent "metaphysics of science" has taken, so we do not take this suggestion as a description of the present state of the field. Rather, we propose that metaphysics of science could potentially be richer and more diverse than what its current state might suggest, and we describe some possible avenues (a priori, nonrealist, not only physics-based) for such a diversification. Perhaps all metaphysics of science will eventually prove to be a posteriori, realist, and based in physics, but we believe that this view must be demonstrated rather than just assumed, and we consider that it is a reasonable attitude to remain open-minded to other options until this demonstration is made.

The present paper is structured as follows: After a description of the distinctive features of scientific metaphysics (Section 1), we examine the two oversimplifications on which, according to us, recent scientific metaphysics has been built (Section 2). In contrast, we show (Section 3) that metaphysics of science should be conceived in a more integrative and less exclusive way, as a metaphysics that takes into account present science as it is, and that this conception opens up the question of how metaphysics of science relates to other metaphysical approaches available in philosophy. The examination of these relations is the aim of Section 4, which we see as our main contribution. By using a three-dimensional metaphysical figure, we demonstrate that a more fertile and diverse metaphysics of science can be built through its articulation with other metaphysical projects, and than this renewed metaphysics of science is richer and philosophically more useful than the quarrelsome and supposedly radical scientific metaphysics of people like Ladyman and Ross.

\section{Self-portrait of scientific metaphysics}

Since the beginning of the 1990s, many philosophical projects have described themselves as parts of an approach or domain called "metaphysics of science" or, more precisely, "scientific metaphysics" (Redhead 1995; Ladyman and Ross 2007; Maudlin 2007; Esfeld 2012, 2013; Ross, Ladyman and Kincaid 2013; French 2014). But what is exactly scientific metaphysics according to its own self-appointed advocates?

A majority of philosophers who portray themselves as "scientific metaphysicians" adhere to three important theses: scientific metaphysics should be i) physics-based, ii) universalist and exclusive, and iii) realist. First, many proponents of scientific metaphysics see physics as the most fundamental science. They wear physics goggles where, for example, Aristotle built his

\footnotetext{
${ }^{5}$ The call for a more diversified metaphysics of science made in the present paper is, however, not unique, as illustrated by (Morganti 2013), and a few others.
} 
metaphysics wearing biology goggles (Cohen 2012), and, in many cases, they tend to overlook the difficulties that this exclusiveness could raise. For example, Maudlin writes:

Metaphysics, insofar as it is concerned with the natural world, can do no better than to reflect on physics. Physical theories provide us with the best handle we have on what there is, and the philosopher's proper task is the interpretation and elucidation of those theories. (Maudlin 2007: 1).

Second, scientific metaphysics is universalist and exclusive in the sense that it seeks to replace a supposedly dominating approach of metaphysics by another dominating ("imperialist") approach, which would be precisely a purely science-based metaphysics. For example, in the first chapter of their book, called "In Defense of Scientism", Ladyman and Ross assert:

The aim of this book is to defend a radically naturalistic metaphysics. By this we mean a metaphysics that is motivated exclusively by attempts to unify hypotheses and theories that are taken seriously by contemporary science. For reasons to be explained, we take the view that no alternative kind of metaphysics can be regarded as a legitimate part of our collective attempt to model the structure of objective reality. (Ladyman and Ross 2007: 1).

In other words, according to this approach, any philosopher interested in understanding objective reality must rely on a metaphysics based on science only, and therefore ultimately on the hypotheses and theories defended in current sciences (which in most cases means, as suggested in the first point above, the hypotheses and theories of current physics).

Third, a majority of proponents of scientific metaphysics adopt scientific realism, namely the view that there exists a reality that is mostly independent of us, that this reality is the truthmaker of our scientific statements, and that we can adequately represent this reality through our scientific tools. Many of them even suggest that scientific realism is a necessary component of every project in metaphysics of science. For example, Esfeld writes:

[...] pursuing the project of a metaphysics of nature evidently presupposes the view that the pretensions to knowledge contained in our scientific theories are not baseless. In other words, some sort of a scientific realism is presupposed. (Esfeld 2009).

It is beyond doubt that realism, and in particular scientific realism, is a strong thesis, and there is much to say in its favor. Nonetheless, by making claims such as the one above, proponents of scientific metaphysics seem to exclude without further examination any form of idealism or pragmatism. And yet these metaphysical approaches have been defended by highly influential figures in the history of philosophy, including scientifically-oriented philosophers (some examples are examined below). In our view, metaphysics of science should perhaps not attach itself too rapidly to a particular conception of the relation between scientific representation and the world.

Importantly, some philosophers interested in metaphysical approaches to science could reject, or have indeed rejected, one or several of the three claims that we have just examined, and indeed several of these philosophers will be mentioned below. But these three claims constitute an important core of ideas shared by the philosophers who have been most radical and vocal in their defense of a scientific metaphysics that could oppose, and eventually replace, more traditional forms of metaphysics. These militant philosophers have aroused much interest in recent years, and, as explained in the Introduction, they are our main targets here. In the next section, we examine what we see as two major oversimplifications on which this recent scientific metaphysics has been built.

\section{Two oversimplifications in recent scientific metaphysics}


Recent scientific metaphysics trumpets that it offers both a diagnosis and a cure. The diagnosis is that current metaphysics is entirely flawed, and the cure is to replace this flawed metaphysics by a new form of metaphysics, based exclusively on the results of current science. ${ }^{6}$ In our view, however, scientific metaphysics makes an imprecise and even erroneous diagnosis, and cannot therefore offer a satisfying cure. The diagnosis is problematic mainly because of two oversimplifications made by the proponents of scientific metaphysics. The first oversimplification concerns the target of scientific metaphysics. Scientific metaphysicians want to fight fiercely an enemy, but who exactly is that enemy? Two main options have been suggested. In the first option, proponents of scientific metaphysics conflate several metaphysical approaches as if they were equivalent or necessarily connected: "a priori", "analytic", "intuitive", "armchair" metaphysics (Ladyman and Ross 2007: 10). As the rest of this paper will demonstrate, these approaches are distinct, and cannot therefore be attacked as if they were all one and the same. In other words, scientific metaphysicians fail here in singling out a precise target, simply because they conflate too many, improperly identified, adversaries. A second option has been to attack a caricatured opponent, namely metaphysicians who would be simultaneously realist and universalist, and would base their reasoning on intuition and a priori considerations. While we do not mean to suggest that such a metaphysical stance has never been defended, we want to emphasize that it is a minority position at best. In what follows, we propose that scientific metaphysics should clarify its own project by identifying more precisely, and perhaps also more cogently, opponents.

The second oversimplification concerns an undue restriction of scientific metaphysics to the three theses mentioned above, namely reduction to physics, universalism, and realism. It seems to us reasonable to remain open-minded to other possible avenues for scientific metaphysics. The idea that all reality "ultimately reduces" to physics is far from obvious. ${ }^{7}$ More importantly, it is simply not true that all projects in science-based metaphysics have been rooted in physics (even if one could argue that they have been assuming ontological physicalism). In fact, one of the most active and precursory areas of metaphysically-oriented philosophy of science in the last decades has arguably concerned the metaphysics of biology, and especially questions related to the metaphysical nature of individuals and species, a debate that has gathered philosophers of biology and biologists alike (Ghiselin 1974, 1988, 1997; Hull 1978, 1980, 1989, etc.) Metaphysical questions raised about biology have continued ever since, under different forms (e.g., Godfrey-Smith 2009; Dupré 2012; Pradeu 2012; Bouchard and Huneman 2013), and they are framed in ways that are clearly independent from physics. ${ }^{8}$

It is also far from obvious that all projects in scientific metaphysics should profess exclusiveness, as if there was only one metaphysical approach or valid ontology. Metaphysics is in general a unifying enterprise, but this does not mean that one single approach will be the only appropriate one, at the expense of all the others. Several projects in science-based metaphysics seem at odds with an exclusive and imperial approach. Some have presented themselves as pluralist (e.g., Cartwright 1989; Mitchell 2003; Wimsatt 2007; Ruphy 2016) or as "promiscuous" (Dupré 1993), and others have defended ontological emergentism (e.g. Humphreys 1997a, 1997b, 2008; Morrison 2012; Guay and Sartenaer 2016). The view that one given approach is uniquely appropriate and

\footnotetext{
6 “[C]ontemporary analytic metaphysics, a professional activity engaged in by some extremely intelligent and morally serious people, fails to qualify as part of the enlightened pursuit of objective truth, and should be discontinued" (Ladyman and Ross 2007: vii; see also Chapter 1)

${ }^{7}$ To our knowledge the main element in favor of this thesis is the fact that other disciplines have to take into account physical laws and, on the other hand, physics does not have, until now, to take into account scientific results from other disciplines. This could well be a perspective artifact. Moreover, if there is such a thing as ontological emergence in nature - as we have more and more reasons to believe - the exclusivity of physics is not sustainable (for a concrete example in chemistry, see Hendry 2010).

${ }^{8}$ What we criticize is the reduction of metaphysics to the discipline of physics (physical laws, models, and theories). We do not take issue with ontological physicalism - the view that everything is or is composed of physical entities (Papineau 2001).
} 
fundamental (in the present case, a metaphysics derived from our best current physical theories) cannot be accepted without demonstration.

Finally, realism is of course a perfectly legitimate metaphysical position, but it should never be accepted without argument as a necessary condition of all metaphysical discourse, as has often been the case in recent scientific metaphysics. One should always keep in mind that realism is a view that is demanding and difficult to demonstrate. Even more importantly for our project, many philosophers who in the past have wanted to build science-oriented metaphysics were not realist. Here Kant is a major example. In a text often neglected by metaphysicians of science, namely the Metaphysische Anfangsgründe der Naturwissenschaft, published in 1786, Kant (2004) provides an antirealist metaphysical foundation for most, if not all, Newton's kinematic and dynamical concepts. For example, using the result of the first Critique and of the Prolegomena, Kant redefines the concept of matter as the movable in space under the categories of quantity (a mathematical notion). Motion becomes a change relatively to a given space (knowing that space is always relative to a cognitive subject). Newton's absolute space is reconstructed as an indefinitely extended sequence of ever larger relative spaces. Based on reformulations like these and their close relations to mathematics, Kant derives general kinematical, like Galileo's addition of speeds principle, and dynamical results, like the necessary existence of an attractive force of infinite range. As argued by Friedman (2013), Kant's approach suggests that nature is at least partly constructed by us. It is, as such, an antirealist position. It is a clear attempt to provide a metaphysical worldview deeply ingrained in the best science of his time, without a commitment to realism. Proponents of scientific metaphysics would have us believe that such an example is not metaphysics at all because, in their view, metaphysics is by definition the study of the mind-independent world. This seems to imply that metaphysics is defined by its subject matter. But this would be strange, since in the history of philosophy metaphysics has mostly been defined by the generality of its claims and its unusual a priori methodology (Macdonald 2005), not by its subject matter. The Kantian tradition continues in contemporary time (e.g., Strawson 1959). Moreover, several of the philosophers currently interested in constructing a worldview on the basis of science are explicitly antirealist or lean toward antirealism - as illustrated by van Fraassen's structural empiricism (2006) or Ruetsche's locaveracity (2015). To argue that these philosophers are not engaged in some kind of metaphysical project based on science is to assert that science does not make sense outside a realist position. This is untenable as the above Kant's example shows.

We are not saying here that scientific realism is erroneous, only that it should not be considered as the only option on the metaphysical table. Presupposing realism leads to excluding without good reasons some possible avenues for metaphysics of science. In the following section, we explain why we defend a broad conception of metaphysics of science, one that does not limit itself in advance to reductionism, universalism, and realism.

\section{Our view of metaphysics of science: a broader and more open-minded framework}

We propose that metaphysics of science must be understood in a much broader and open-minded way than many proponents of "scientific metaphysics" have suggested. At the most general level, we understand metaphysics of science as a form of metaphysics committed to, and therefore fully engaged with, today's sciences (in all their diversity: we include physical sciences, biological sciences, social sciences, etc.). More precisely, four crucial features characterize the conception of metaphysics of science that we want to promote. First, its reference is science as it is really done, and not an idealized vision of science. To this end, metaphysicians of science must take into account the best scientific theories but also pay special attention to scientific practices (e.g., in terms 
of modeling, simulations, measurement, etc.) (Hacking 1983; Radder 2003; Chen 2016). ${ }^{9}$ Second, its point of reference is current science, and not science of the past, nor science of a hypothetical future. ${ }^{10}$ Third, metaphysics of science does not imply an automatic adhesion to such theses as scientific realism, reductionism, physicalism, or materialism. We do not deny the importance of these debates, but we consider that arguments in favor or against scientific realism, reductionism, etc., are precisely part of what metaphysics of science is about. They are not already settled. ${ }^{11}$ In particular, it is perfectly possible for both realists and antirealists to do "metaphysics of science" in the sense suggested here. To give but one example, van Fraassen's structural empiricism (van Fraassen 2006, 2008), which, as explained, is a form of antirealism, qualifies, in our definition, as an instance of "metaphysics of science," because it aims at developing a worldview grounded in current science (even though it is a non-realist view, and even though van Fraassen himself would reject the label "metaphysical"). Fourth, metaphysics of science is a project that involves all experimental sciences, and not simply one particular science. In contrast to those who think that metaphysics of science must necessarily be, "ultimately", the metaphysics of physics (e.g., Maudlin 2007), we claim that different scientific fields give rise to distinct scientific images, and that reconciling these different images is one of the noblest and most important tasks for metaphysics of science (Braillard et al. 2011; Guay and Pradeu 2016).

In our view, the most fruitful projects in metaphysics of science are those that combine locality and generality. In such cases, metaphysics of science starts with the study of one science, which in almost all cases applies to a limited domain of the world (locality). In other words, this form of metaphysics of science mainly investigates the specific ontological commitment of the various representations that exist in one science. The limited domain implies a limited worldview, i.e., a local scientific image (van Fraassen 1980). But, in a second step, metaphysics of science can, and should, seek generalization. More precisely, it should compare and possibly unify the different local images offered by different approaches within one science (intrascientific unification), as well as the different local images offered by different sciences (interscientific unification) (in accordance with what Godfrey-Smith (2014) calls a "philosophy of nature"). This is unification by combination, not unification by reduction (as in some versions of logical positivism) (Guay and Pradeu 2016). Of course, one can be a radical pluralist with regard to the scientific images of the world; in other words, one can consider that each science offers its own specific image of the world. But metaphysicians of science should always be very careful with divisions as fragile as disciplinary divisions: perhaps our division of sciences into sub-sciences is contingent and grounded in bad reasons (we know that it has changed in the course of the history of science), and therefore two natural moves for metaphysicians of science will be first to take with great care a metaphysical claim that would be said to be true only for one science (physics or biology, for example), and second to always try to determine whether (and under which conditions) a given metaphysical claim can be extended beyond the domain where it has been originally formulated.

Overall, then, we defend a general, inclusive, and open-minded conception of metaphysics of science, with an insistence on the necessity for metaphysics of science to be deeply anchored in real science, and to aim at a unification of the different worldviews offered by distinct scientific domains. In the next section, we show that this more integrative conception of metaphysics of science leads us to explore how it can relate to, and interact with, other metaphysical approaches available in present-day philosophical debates.

\section{Understanding the relations of metaphysics of science to other forms of metaphysics}

\footnotetext{
${ }^{9}$ In general, metaphysicians of science have focused on theories, and have tended to neglect the importance of scientific practices.

${ }^{10}$ As, for instance, when some philosophers of science claim that statements such as law-like generalizations will be true of biology "when it is truly scientific."

${ }^{11}$ For a similar position, see (Baron 2016).
} 
The main lesson of the previous sections is that, if it is to be precise and interesting, metaphysics of science must situate itself in relation to other forms of metaphysics and these alternative forms must be well-identified. In this section, we try to better characterize metaphysics of science by comparing it with other metaphysical approaches. We argue that the most appropriate picture of current metaphysical "battlefield" is not, as is often suggested, a binary opposition (i.e., "scientific metaphysics" vs. "traditional metaphysics"), but rather a three-dimensional figure, or "metaphysical box" (Figure 2).

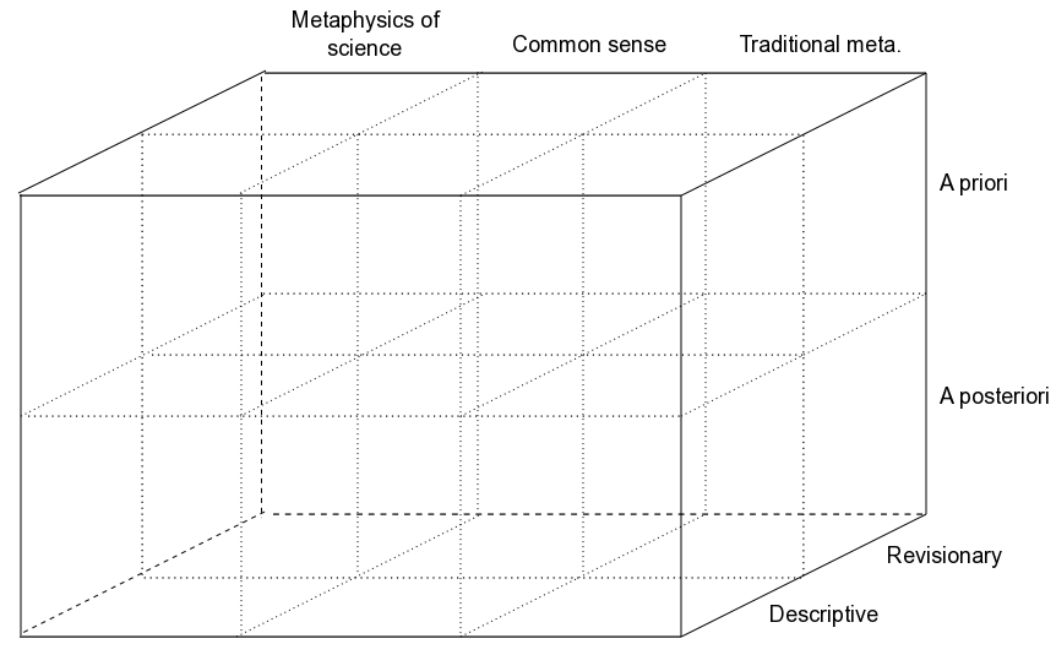

Figure 2: The metaphysical box

The first axis of the box distinguishes "descriptive metaphysics" from "revisionary metaphysics," while the second axis distinguishes a priori from a posteriori metaphysics, and finally the third axis distinguishes "common-sense metaphysics", "traditional metaphysics" and "metaphysics of science." The descriptive/revisionary dimension divides metaphysical projects between the ones that do not aim to revise how we think, and those that do. The former understands metaphysics as a clarificatory enterprise, the later as a revolutionary endeavor. The a priorila posteriori axis distinguishes between two families of methods, the first based on theoretical deduction, the second on empirical methods. Finally, the third axis denotes where the authority and the main interlocutors of a particular metaphysical project lie; for the metaphysics of science, they lie in scientific results, practices and communities; for commonsense metaphysics, they lie in our conceptual scheme, intuitions, and/or everyday language; finally, for traditional metaphysics, they lie in the lessons drawn from the history of philosophy. ${ }^{12}$

This metaphysical box is useful for several reasons, four of which are explored here. ${ }^{13}$ First, it can be used to locate, and thereby to better characterize, specific metaphysical projects. To give just one example, Peter Strawson's landmark book Individuals, An Essay in Descriptive

\footnotetext{
12 This last axis does not imply as strong oppositions as the other two. A given metaphysical project could submit to more than one authorities (for example, Wiggins's (2001) sortalism combines a traditional approach rooted in Aristotle's Categories and a commonsense and "ordinary language" approach (Ferner 2016)). However, there is usually only one that justifies the project as a whole.

${ }^{13}$ We think that our metaphysical box could be used in other ways and for different purposes. We hope that other philosophers will lay their hands on it and use it in novel ways.
} 
Metaphysics (1959) puts forward a descriptive, a priori, and common sense-based metaphysics. We believe that situating existing metaphysical projects within the figure can help clarify them, and facilitate comparisons between different projects. The second and related use of the box is to make it clear that available metaphysical projects are much more diverse than usually described. Thus, even though the notion of descriptive metaphysics is associated with the figure of Strawson, the box suggests that Strawson's approach is not the only way of doing descriptive metaphysics; it paves the way for a descriptive metaphysics that could be a posteriori and/or based on science (we explore these possibilities below). Finally, two uses of the box center on the metaphysics of science. On the one hand, it suggests that metaphysics of science could potentially take several different forms: it could be revisionary or descriptive, and a posteriori or a priori. All these options seem worth examining. On the other hand, the box helps us see how metaphysics of science relates to, and can be combined with, other approaches in metaphysics. In what follows, we first define the seven metaphysical projects distinguished by the axes of our box, and then ask how these different projects relate to metaphysics of science.

\subsection{How to define the metaphysical projects that appear in the box}

Famously, the opposition between descriptive and revisionary metaphysics is found in Strawson's work (1959). Descriptive metaphysics is the study of our fundamental conceptual framework. From a historical point of view, the archetypal figure of descriptive metaphysician is Kant (1781/1999), but Aristotle can be understood also as an example. ${ }^{14}$ Descriptive metaphysics is "universal", in the sense that it elucidates the universal and most profound structure of human thinking, found, Kant believes, across all space and time. Descriptive metaphysics does not aim to reform the structure of our thought or to provide a better conceptual framework to understanding the world. According to the proponents of descriptive metaphysics, this basic structure of our knowledge is therefore fundamental and always present.

Revisionary metaphysics aims at proposing a novel and better conceptual framework than the ones already available, and more generally it calls for a reform of existing metaphysics. Prominent examples of revisionary metaphysicians in the history of philosophy include Descartes, Leibniz, and Berkeley. These philosophers did not just argue that metaphysical reform was possible, they sustained that such a reform was needed to properly understand the world.

Common-sense metaphysics is the study of the categories of the conceptual framework that we use to navigate in ordinary life ("person," "belief," "causality," and "promise" are possible examples belonging to that conceptual framework). Common-sense metaphysics is to a large extent the study of the "manifest image" in the sense of Sellars (1968), which is the image through which humans perceive themselves and perceive the world around them. This structure is all the more important because it contains essential normative concepts. It should also be noted that this kind of metaphysics has a connection to the phenomenological tradition. Importantly, common-sense metaphysics does not necessarily amount to descriptive metaphysics (which, as we saw, focuses on the fundamental and universal structure of human thought). Indeed, some common-sense categories can be culture-dependent, others not. Some can be related to the basic cognitive conceptual structure of all humans, while others depend on a certain kind of learning (scientific or otherwise). More surprisingly, common-sense metaphysics can even be revisionary. A nice example is Berkeley, who offered a metaphysics that was a priori and based on common sense, but also revisionary (in particular when it calls for the elimination of the very idea of matter, a notion coming from science).

Traditional metaphysics is the study of the most potent metaphysical concepts used to describe the world and our access to it. These concepts are generally situated at a fundamental level,

\footnotetext{
${ }^{14}$ As is well-known, Strawson himself sees Kant and Aristotle as major representatives of descriptive metaphysics.
} 
for example "substance", "essence", "entelecheia", "tropes", etc. Traditional metaphysics is grounded in three main, sometimes overlapping, considerations: history, intuition, and conceptual analysis. Traditional metaphysics generally situates itself within the historical context of past metaphysical claims. For example, Aristotle, in his Metaphysics, systematically starts his analyses with an examination of previous thoughts, illustrating thereby his personal conception of the dialectical method. Leibniz also offers an instance of traditional metaphysics, in particular when he tries (in his Discourse on Metaphysics and many other places) to partly return to Scholastic notions despite the critiques of Descartes. Much of Anglophone twentieth century "analytic metaphysics" also belongs to the category of "traditional metaphysics", as illustrated, for example, by the NeoAristotelianism of David Wiggins (Wiggins 2001). ${ }^{15}$ These analytic approaches also illustrate the fact that intuition and conceptual analysis often play an important role in what we call "traditional metaphysics". Many of these approaches aim to explicate the way our language frames our thinking about the world. Yet, they cannot be assimilated to "common sense" metaphysics, because it seems clear that concepts such as "entelecheia" or "tropes" are not used to navigate in ordinary life and are not grounding the concepts that are used. In other words, they are not concepts structuring the manifest image.

Finally, metaphysics of science has already been defined above. Any metaphysical project anchored in current science belongs to metaphysics of science (in our sense). By contrast with the alternative projects, metaphysics of science has no particular deference to our common conceptual scheme, to our intuitions, or to the philosophical tradition.

It is not always a simple task to find clear examples for each possibility in the box. Some philosophies mix a priori and a posteriori methods depending on the moment. For others, where they put the ultimate authority is subject to interpretation. Nevertheless, this three-dimensional figure is a good tool to understand how a particular position is situated. Kant and Strawson are both a priori descriptive metaphysicians. But only Strawson refers to a commonsense approach. By contrast, Kant is in dialogue with the metaphysicians of the past and, more so, with the science of his time (Friedman 2013). ${ }^{16}$ Let us now explain how metaphysics of science relate to the different metaphysical approaches that appear in the metaphysical box.

\subsection{How do these different projects relate to metaphysics of science?}

One lesson that can be drawn from the detailed description of these axes is a better characterization of current "scientific metaphysics." "Scientific metaphysics" (in the sense of Redhead 1995; Ladyman and Ross 2007; Maudlin 2007; Esfeld 2012, 2013; French 2014, among others) is just one way of doing "metaphysics of science": it is an a posteriori and revisionary approach to metaphysics of science (see Figure 3)).

\footnotetext{
15 Note that, contrary to the standard literature, we do not define traditional metaphysics by a method (a priori) or modal language (necessary assertions). We define traditional metaphysics by the kind of authority involved in the research, namely the history of philosophy. Our approach is related to Paul's (2012) one. Like us she does not define metaphysics by its method; contrary to us, though, she defines metaphysics by its subject matter.

${ }^{16}$ It is also possible to claim that Kant founded his ontology on common sense and only at a letter stage sought compatibility with scientific results.
} 


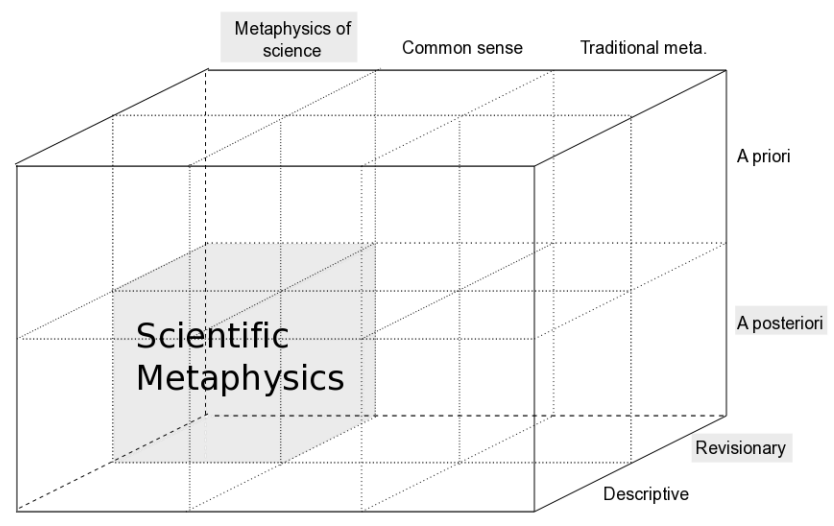

Figure 3: The position of scientific metaphysics in the box

In scientific metaphysics, it is not enough for a metaphysical proposition to be compatible with current science. It must be endogenous to the empirical enterprise of a given science (generally physics), i.e, it must be derived from that science. Consequently, it is a posteriori, in the sense that it relies ultimately on the empirical methods of scientific inquiry. Moreover, it is typically revisionary, especially since its proponents suggest that a new "conceptual structure" should be modified or abandoned all together (e.g., a new notion of causality, or a new way to carve the world into small "objects": see Ladyman and Ross 2007; French 2014). The box, however, suggests that a project in metaphysics of science is not necessarily a posteriori and revisionary. This leads us to the next two lessons.

The second lesson of the box is that metaphysics of science can be descriptive, and also $a$ priori. While metaphysics of science is often considered as necessarily revisionary, descriptive metaphysics is almost always understood as a form of a priori metaphysics. But a project in descriptive metaphysics can in fact be a priori or a posteriori. This plurality of methods is already implicit in Strawson's approach. Strawson assumes that there is a connection between the language spoken by a community and the conceptual scheme of that community (Haack 1979). This opens the door to an a posteriori, and possibly scientific, study of language in order to get to the descriptive ontology of this community. On the other hand, if the project is a priori, it says that we can get access to the fundamental structure of our thought using transcendental inquiry, pure introspection or conceptual analysis, and in that case it bears no relation to science (e.g., Strawson 1959). Beyond a linguistic approach, an a posteriori descriptive metaphysics can consider that the description of the fundamental structure of our thought must take the form of the basic study of the human cognitive conceptual structure given by the evolution of our species. In that case, descriptive metaphysics will draw on the lessons given by the cognitive sciences, and this form of descriptive metaphysics will be "naturalized", and even scientific. One possible example of such a scientific descriptive metaphysics is offered by the work of neuroscientist Stanislas Dehaene. Studying in particular Amazonian indigene cultures, Dehaene shows that some mathematical concepts and thought processes (including basic geometry and the mapping of numbers onto space) are universal, while others strongly depend on the culture to which the individual belongs (Dehaene 2006, 2008). This suggests the possibility of a naturalized, cognitive science-based, descriptive metaphysics. This also confirms that one of the ways the metaphysical box can be philosophically useful is by suggesting that some binary oppositions are oversimplified, and should therefore be avoided. Even though several approaches within descriptive metaphysics have been "a-scientific", we see here that science-based approaches in descriptive metaphysics are perfectly possible and are worth investigating. 
In the same vein, even though "scientific metaphysics" presents itself as anti-a priori", metaphysics of science can also be a priori, in particular when it aims at reforming our conceptual structure on the basis of an analysis of formal sciences like mathematics (examples include Pythagoras and Kant). Descartes is also an example. In Les Principes de la Philosophie (1973), after obtaining, by metaphysical analysis, the general notions that apply to all things (substance, duration, order and number), Descartes derives, in contrast to the properties of the intellectual substance, the fundamental properties of the corporal substance: extension in three dimensions and movement (all mathematical properties). Armed with this result and a certain conception of the rationality of God, he subsequently infers important claims about vacuum, inertia, causality, etc. This metaphysical approach of science and, in particular, of physics, is a priori and necessary. The resultant metaphysical and empirical claims must be followed by nature. Overall, then, the box makes it possible to avoid hasty and simplified views, and enrich our conception of what metaphysics of science can be.

The third lesson of the box is that, for metaphysics of science, the interesting opponents are not the most obvious ones. The aim of the proponents of "scientific metaphysics" (especially Ladyman and Ross 2007) seems to be to demolish a form of metaphysics that is both a priori, based on common sense, and descriptive. But, if not a straw man, this is clearly not a very powerful and interesting enemy, and such rhetoric erroneously suggests that scientific metaphysics has got the upper hand over all other forms of metaphysics. This opposition between "scientific" and "nonscientific" approaches is based on an oversimplification of current conceptions in metaphysics, and it hides some of the most important and difficult questions and oppositions. Let us discuss two of these oppositions that can be found along the same axis.

(1) The opposition between scientific metaphysics and an a priori revisionary metaphysics of science is potentially interesting, because it denotes the opposition between a priori and $a$ posteriori dimensions of revisionary metaphysics of science. In empirical science, even if an $a$ posteriori justification is necessary to know which particular entities exist, perhaps an a priori justification is sufficient to identify which categories of entities exist or could exist. Empirical methods are notoriously limited when modality is involved. This methodological debate, internal to the revisionary metaphysics of science project, is surprisingly absent from the literature. Since scientific metaphysics lays claim to a dominant position, this seems unjustified.

(2) The opposition between descriptive and revisionary a posteriori metaphysics of science is even more problematic. If the sciences that take humans as their subject of study (including social, cognitive, and biological sciences) reveal the existence of stable and universal mental structures, in what way is a truly revisionary metaphysical project even possible? In other words, how is this collective enterprise called 'science' able to transcend the fundamental conceptual framework? If it cannot, scientific metaphysics should be if not abandoned at least revised. If it can, the articulation between the fundamental framework and the new proposed conceptual framework should be elucidated. It is not known whether scientific concepts are refinements or compositions built on a stable conceptual framework, or are rather radically new concepts. In our view, this last question is particularly important, even though the possibility of a descriptive metaphysics of science, and, conversely, the influence of our human cognitive structures on the construction of our sciences (and, consequently, our metaphysics of science) are two issues that have been almost entirely neglected in recent debates within the metaphysics of science. If it is true (as seems likely) that we cannot do science without being influenced by entrenched cognitive structures, then it becomes crucial, for both philosophy and science itself, to investigate the way descriptive metaphysics and metaphysics of science may dialogue, and influence each other. ${ }^{18}$

\footnotetext{
${ }^{17}$ For example, Ladyman \& Ross (2007: 7) write (against Lowe (2002)): "we have no good reasons for thinking that a priori metaphysical knowledge is possible."

${ }^{18}$ A key question - especially in the context of a realist metaphysical project - will be how scientific representations manage to get around these entrenched cognitive structures.
} 
A final difficult question concerns interactions between metaphysical approaches located along the metaphysics of science-traditional metaphysics axis. As briefly illustrated, the other axes reflect explicit oppositions, so it seems difficult to conceive a metaphysical project that would be simultaneously a priori and a posteriori, or descriptive and revisionary (though rare exceptions could probably be found). The former axis, however, reflects only the main basis on which metaphysics should be built, and here again exclusiveness is possible, but not necessary. In other words, some philosophers might think that metaphysics must be guided exclusively by science, at the expense of a commonsense and/or traditional basis. The difficulty that immediately arises is how to explain the relation between metaphysics of science and the other metaphysical projects? Are they simply illusions or is there some kind of conceptual reduction involved? For example, can we reduce the fundamental conceptual structure underlying the manifest image to the metaphysics of science? Philosophers can perfectly hold that a satisfying metaphysics will be based on a balance of inputs coming from science, common sense, and traditional metaphysics. Morganti (2013) promotes such an articulation of science, common sense, and traditional metaphysics on the ground that metaphysics cannot be directly read off from scientific theories and practices. On the other hand, common sense and traditional metaphysics, as useful as they are, do not have the same kind of access science has to the world. In consequence, a dual metaphysical project might be regarded the preferable strategy. Another attitude is to view traditional and common sense metaphysics as sources of inspiration for a scientifically informed metaphysics: this is what French and McKenzie have described as a "Viking" attitude towards metaphysics, or a way of seeing other metaphysical discourses as a useful "toolbox" (French 2014; French and McKenzie 2012). As mentioned before, we too favor the view that metaphysics of science must be grounded in science but not exclusively in science, and we agree that both traditional metaphysics and common sense often influence science-based worldviews.

Let us give just one example. Our past exploration of the notion of individuality across different sciences, especially physics and biology, has shown that the criteria used to determine whether or not something is an individual within a given experimental science are "classic" criteria coming from traditional metaphysics (e.g., permanence, uniqueness, and the existence of boundaries) ${ }^{19}$ (Guay and Pradeu 2016). The relative weight of these criteria, and sometimes their specific meaning, change according to the domain of science under consideration, but the criteria themselves are most of the time the same. Moreover, any comparison of the meaning of the word "individual" between two different sciences is likely to be rooted in these classic criteria. Not only, then, do most metaphysical concepts used in science (law, causality, symmetry, disposition, individual...) have their origin outside science and many metaphysical approaches have had a strong influence on scientific development (Cushing 1998, Ryckman 2005), but, additionally, the significance of several concepts within science can depend on classic criteria that have been used by traditional metaphysics for centuries. Even if we strongly believe that science is, for the most part, autonomous, some of its basic conceptual structure comes from other metaphysical approaches.

In our view, all these questions, which have been suggested to us by the metaphysical box, are much more complex and exciting than the question of how scientific metaphysics can replace traditional metaphysics. We can only hope that they will be explored by metaphysicians of science in future studies.

\section{Conclusion}

In this paper, we have defended a qualified version of metaphysics of science. According to this version, metaphysics must be built through a constant dialogue with science - but not with science

\footnotetext{
${ }^{19}$ Two possible examples among many others are the debate about units of selection as individuals in biology and philosophy of biology and the debate over the role of the principle of indiscernibility in physics and philosophy of physics.
} 
only. We have shown that the recent trend called "scientific metaphysics" (which claims that science should be the sole source for metaphysics) has oversimplified and misrepresented the current metaphysical landscape, and has therefore missed some of the most significant challenges for anyone interested in the combination or conflict between science and metaphysics. We have proposed a "metaphysical box" (Figure 2), which illustrates the complexity of the available positions by distinguishing a priori and a posteriori metaphysics, descriptive and revisionary metaphysics, and finally traditional, science-based, and commonsense-based metaphysics. In our view, the most challenging and interesting issue concerns the combination of these different metaphysical approaches, rather than the proclamation that one approach - here scientific metaphysics - should replace the others.

Building a sensible and open-minded metaphysics of science (i.e., one that will tell us what our world is most probably like, and how we can best understand it, through the combination of the lessons coming from science and from different metaphysical approaches) will likely require a significant switch in philosophy curricula. Indeed, many philosophers of science, especially when they are trained in a specific subfield (say, philosophy of biology or philosophy of physics) see metaphysics with suspicion, and sometimes even contempt. In parallel, a majority of philosophers who self-identify as metaphysicians are ignorant of the sciences and the philosophy of science. If we are right to say that metaphysics of science must emerge from the patient and careful combination of the local images of the world offered by different sciences, as well as the combination of these scientific lessons with those offered by traditional metaphysics and common sense metaphysics, then it seems clear that such a project will require a new generation of philosophers, trained in all these fields, and respecting them all.

\section{Acknowledgments}

We thank Max Kistler and all the members of the ANR-funded project on Metaphysics of Science (ANR-12-BSH3-0009), in particular Jean Gayon, Philippe Huneman, Pascal Ludwig, and Stéphanie Ruphy. In addition, we thank Alexander Bird, Mauro Dorato, John Dupré, Adam Ferner, James Ladyman, Matteo Morganti, Alyssa Ney, Christian Sachse, and Francis Wolff for comments on previous versions of this paper. Thomas Pradeu has received funding from the European Research Council (ERC) under the European Union's Horizon 2020 research and innovation programme grant agreement $n^{\circ} 637647-I D E M$.

\section{References}

Armstrong, D.M. 1978. A Theory of Universals. Vol. Universals and Scientific Realism II. Cambridge: Cambridge University Press.

Baron, Sam. 2016. “Metaphysics as Fairness.” Synthese 193 (7): 2237-59.

Bird, Alexander. 2007. Nature's Metaphysics: Laws and Properties. Oxford: Clarendon Press.

Bouchard, Frédéric, and Philippe Huneman, eds. 2013. From Groups to Individuals: Evolution and Emerging Individuality. Vienna Series in Theoretical Biology. The MIT Press.

Braillard, Pierre-Alain, Alexandre Guay, Cyrille Imbert, and Thomas Pradeu. 2011. "Une Objectivité Kaléidoscopique : Construire L’image Scientifique Du Monde.” Philosophie, no. 110 (Été): 46-71.

Carnap, Rudolf. 1931. “Überwindung Der Metaphysik Durch Logische Analyse Der Spradle.” Erkenntnis 2 (January): 219-41. 
Carnap, Rudolf, Hans Hahn, and Otto Neurath. 1929. Wissenschaftliche Weltauffassung: Der Wiener Kreis. Edited by the Verein Ernst Mach. Wien: Artur Wolf Verlag.

Cartwright, Nancy. 1989. Nature’s Capacities and Their Measurement. Oxford: Oxford University Press.

Chakravartty, Anjan. 2007. A Metaphysics for Scientific Realism: Knowing the Unobservable. Cambridge: Cambridge University Press.

Chen, Ruey-Lin. 2016. "Experimental Realization of Individuality.” In Individuals Across the Sciences, edited by Alexandre Guay and Thomas Pradeu, 348-70. New York, NY: Oxford University Press.

Cohen, S. Marc 2012. "Alteration and Persistence: Form and Matter in the Physics and De Generatione et Corruptione." In The Oxford Handbook to Aristotle, edited by Christopher Shields, 205-26. New York: Oxford University Press.

Cushing, James T. 1998. Philosophical Concepts in Physics: The Historical Relation Between Philosophy and Scientific Theories. Cambridge: Cambridge University Press.

Descartes, René. 1973. Oeuvres Philosophiques. Edited by Ferdinand Alquié. Vol. 3. Paris: Garnier Frères.

Dehaene, Stanislas, Véronique Izard, Pierre Pica, and Elizabeth Spelke. 2006. "Core Knowledge of Geometry in an Amazonian Indigene Group." Science 311 (5759): 381-84.

Dehaene, Stanislas, Véronique Izard, Elizabeth Spelke, and Pierre Pica. 2008. "Log or Linear? Distinct Intuitions of the Number Scale in Western and Amazonian Indigene Cultures." Science 320 (5880): 1217-20.

Dupré, John. 1993. The Disorder of Things: Metaphysical Foundations of the Disunity of Science. Harvard University Press.

Dupré, John. 2012. Processes of Life: Essays in the Philosophy of Biology. Oxford: Oxford University Press.

Ellis, Brian. 2001. Scientific Essentialism. Cambridge: Cambridge University Press.

Esfeld, Michael. 2009. "Hypothetical Metaphysics of Nature.” In The Significance of the Hypothetical in the Natural Sciences, edited by Michael Heidelberger and Gregor Schiemann, 341-64. Berlin: Walter de Gruyter.

Esfeld, Michael. 2012. Physique et Métaphysique: Une Introduction à La Philosophie de La Nature. Lausanne: Presses polytechniques et universitaires romandes.

Esfeld, Michael. 2013. "Metaphysics and Science.” In Encyclopedia of Philosophy and the Social Sciences, edited by Byron Kaldis, 601-4. Thousand Oaks CA: SAGE.

Ferner, Adam M. 2016. Organisms and personal identity: biological individuation and the work of David Wiggins. Routledge, Abingdon, Oxon ; New York, NY

French, Steven. 2014. The Structure of the World: Metaphysics and Representation. New York: Oxford University Press.

French, Steven, and Décio Krause. 2006. Identity in Physics: An Historical, Philosophical, and Formal Analysis. Oxford: Oxford University Press.

French, Steven, and Kerry McKenzie. 2012. "Thinking Outside the Toolbox: Towards a More Productive Engagement between Metaphysics and Philosophy of Physics.” European Journal of Analytic Philosophy 8 (1): $42-59$.

Friedman, Michael. 2013. Kant's Construction of Nature: A Reading of the Metaphysical Foundations of Natural Science. Cambridge: Cambridge University Press.

Ghiselin, M.T. 1974. “A Radical Solution to the Species Problem.” Systematic Biology 23 (4): 536-44.

Ghiselin, Michael T. 1988. "The Individuality Thesis, Essences, and Laws of Nature.” Biology and Philosophy 3 (4): 467-74. 
Ghiselin, Michael T. 1997. Metaphysics and the Origin of Species. SUNY Series in Philosophy of Biology. State University of New York Press.

Godfrey-Smith, Peter. 2009. Darwinian Populations and Natural Selection. Oxford: Oxford University Press.

Godfrey-Smith, Peter. 2014. Philosophy of Biology. Princeton Foundations of Contemporary Philosophy. Princeton: Princeton University Press.

Guay, Alexandre, and Thomas Pradeu. 2016. "Introduction: Progressive Steps toward a Unified Conception of Individuality across the Sciences." In Individuals Across the Sciences, edited by Alexandre Guay and Thomas Pradeu, 1-21. New York: Oxford University Press.

Guay, Alexandre, and Olivier Sartenaer. 2016. “A New Look at Emergence. Or When after Is Different.” European Journal for Philosophy of Science 6 (2): 297-322.

Haack, Susan. 1979. “Descriptive and Revisionary Metaphysics.” Philosophical Studies 35 (4): 361-71.

Hacking, Ian. 1983. Representing and Intervening: Introductory Topics in the Philosophy of Natural Science.

Cambridge University Press.

Hendry, Findlay Robin. 2010. “Ontological Reduction and Molecular Structure.” Studies in History and Philosophy of Modern Physics 41 (2): 183-91.

Hull, David L. 1978. “A Matter of Individuality.” Philosophy of Science 45 (3): 335-60.

Hull, David L. 1980. "Individuality and Selection.” Annual Review of Ecology and Systematics 11: 311-32.

Hull, David L. 1989. The Metaphysics of Evolution. SUNY Series in Philosophy of Biology. State University of New York Press.

Humphreys, Paul W. 1997a. “Emergence, Not Supervenience.” Philosophy of Science 64 (4): S337-45.

Humphreys, Paul. 1997b. “How Properties Emerge.” Philosophy of Science 64 (1): 1-17.

Humphreys, Paul. 2008. "Synchronic and Diachronic Emergence.” Minds and Machines 18 (4): 431-42.

Kant, Immanuel. 1999. Critique of Pure Reason. Edited and translated by Paul Guyer and Allen W. Wood. Cambridge: Cambridge University Press.

Kant, Immanuel. 2004. Metaphysical Foundations of Natural Science. Edited and translated by Michael Friedman. Cambridge Texts in the History of Philosophy. Cambridge: Cambridge University Press.

Ladyman, James, and Don Ross. 2007. Every Thing Must Go: Metaphysics Naturalized. Oxford: Oxford University Press.

Ladyman, James, and Don Ross. 2013. “The World in the Data.” In Scientific Metaphysics, edited by Don Ross, James Ladyman, and Harold Kincaid, 108-50. Oxford: Oxford University Press.

Lewis, David K. 1973. Counterfactuals. Oxford: Basil Blackwell.

Lowe, E.J. 2002. A Survey of Metaphysics. Oxford: Oxford University Press.

Lowe, E.J. 2006. The Four-Category Ontology: A Metaphysical Foundation for Natural Science. Oxford: Oxford University Press.

Macdonald, Cynthia. 2005. Varieties of Things: Foundations of Contemporary Metaphysics. Malden, MA: Blackwell. Maudlin, Tim. 2007. The Metaphysics Within Physics. New York: Oxford University Press. 
Mitchell, Sandra D. 2003. Biological Complexity and Integrative Pluralism. Cambridge Studies in Philosophy and Biology. Cambridge: Cambridge University Press.

Morganti, Matteo. 2013. Combining Science and Metaphysics: Contemporary Physics, Conceptual Revision and Common Sense. New Directions in the Philosophy of Science. Palgrave Macmillan.

Morrison, Margaret. 2012. “Emergent Physics and Micro-Ontology.” Philosophy of Science 79 (1): 141-66.

Mumford, Stephen, and Matthew Tugby, eds. 2013. Metaphysics and Science. Mind Association Occasional Series. Oxford: Oxford University Press.

Ney, Alyssa. 2012. “Neo-Positivist Metaphysics.” Philosophical Studies 160 (1): 53-78.

Papineau, David. 2001. "The Rise of Physicalism.” In Physicalism and Its Discontents, edited by Carl Gillett and Barry Loewer, 3-36. Cambridge: Cambridge University Press.

Paul, L. A. 2012. 'Metaphysics as Modeling: The Handmaiden's Tale'. Philosophical Studies 160 (1): 1-29. doi:10.1007/s11098-012-9906-7.

Pradeu, Thomas. 2012. The Limits of the Self: Immunology and Biological Identity. Translated by Elizabeth Vitanza. New York: Oxford University Press.

Radder, Hans, ed. 2003. The Philosophy of Scientific Experimentation. Pittsburgh, PA: University of Pittsburgh Press.

Redhead, Michael. 1995. From Physics to Metaphysics. Cambridge: Cambridge University Press.

Ross, Don, James Ladyman, and Harold Kincaid. 2013. Scientific Metaphysics. Oxford: Oxford University Press.

Ruetsche, Laura. 2015. “The Shaky Game +25, or: On Locavoracity.” Synthese 192 (11): 3425-42.

Ruphy, Stéphanie. 2016. Scientific Pluralism Reconsidered: A New Approach to the (dis)unity of Science. Pittsburgh: University of Pittsburgh Press.

Ryckman, Thomas. 2005. The Reign of Relativity: Philosophy in Physics 1915-1925. Oxford Studies in the Philosophy of Science. New York: Oxford University Press.

Sellars, Wilfrid. 1968. Science, Perception and Reality. International Library of Philosophy and Scienctific Method. London: Routledge.

Strawson, P.F. 1959. Individuals: An Essay in Descriptive Metaphysics. University Paperbacks. London: Methuen \& Co.

Van Fraassen, Bas C. 1980. The Scientific Image. Clarendon Library of Logic and Philosophy. Oxford: Clarendon Press.

van Fraassen, B.C. 2006. "Structure: Its Shadow and Substance." The British Journal for the Philosophy of Science 57 (2): 275-307.

van Fraassen, Bas C. 2008. Scientific Representation: Paradoxes of Perspective. Oxford: Clarendon Press.

van Inwagen, Peter. 2002. Metaphysics. Second edition. Boulder CO: Westview Press.

Wiggins, David. 2001. Sameness and Substance Renewed. Cambridge: Cambridge University Press.

Wimsatt, William C. 2007. Re-Engineering Philosophy for Limited Beings: Piecewise Approximations to Reality. Harvard University Press. 